This item was submitted to Loughborough's Research Repository by the author.

Items in Figshare are protected by copyright, with all rights reserved, unless otherwise indicated.

\title{
Gambled price discounts: A remedy to the negative side effects of regular price discounts
}

\section{PLEASE CITE THE PUBLISHED VERSION}

https://doi.org/10.1509/jm.12.0408

\section{PUBLISHER}

American Marketing Association

\section{VERSION}

AM (Accepted Manuscript)

\section{PUBLISHER STATEMENT}

This work is made available according to the conditions of the Creative Commons Attribution-NonCommercialNoDerivatives 4.0 International (CC BY-NC-ND 4.0) licence. Full details of this licence are available at: https://creativecommons.org/licenses/by-nc-nd/4.0/

\section{LICENCE}

CC BY-NC-ND 4.0

\section{REPOSITORY RECORD}

Alavi, Sascha, Torsten Bornemann, and Jan Wieseke. 2015. "Gambled Price Discounts: A Remedy to the Negative Side Effects of Regular Price Discounts". Loughborough University. https://hdl.handle.net/2134/33440. 


\section{Gambled Price Discounts-A Remedy to the Negative Side Effects of Regular Price Discounts}

In the context of price discounts, a special type of price promotion, where savings depend on the outcome of a gamble and are thus uncertain, has recently achieved some popularity. With regard to such gambled price discounts (GPDs), the question arises as to whether these discounts incur the negative reference price effect—a downward shift in customers' internal reference price (IRP), which is often associated with regular price discounts (RPDs). On the basis of several studies, including two longitudinal field experiments, the authors find that GPDs indeed alleviate the negative reference price effect: IRPs and actual repurchasing tend to be lower for RPDs than for GPDs and a no-discount control condition. Moreover, they explore the psychological underpinnings of these effects and show that the different consequences of GPDs versus RPDs on IRPs are more pronounced if information regarding product quality is limited. The authors show that findings are robust to variations of GPD discount levels and the probability of winning.

Keywords: uncertainty, reference price, gambled price discounts, price promotion, marketing innovation 
Consider entering a retail store, where a salesclerk offers a price promotion: you draw a ticket and receive your desired purchase item with a 50-50 chance at either half price or full price. Now, contrast this situation with a second purchase at another store, where an employee hands out a discount coupon offering an unconditional 25\% off your desired item. The latter situation describes a regular price discount (RPD), where the customer receives the indicated savings with certainty, while the first situation depicts a gambled price discount (GPD), where the customer receives a discount that is contingent on the outcome of a probabilistic gamble and is thus uncertain. Research provides evidence that RPDs might act as a strong purchase incentive, but at the same time lower customers’ internal reference price (IRP) (e.g., DelVecchio, Krishnan, and Smith 2007). This reduction leads to lower repurchasing levels after the promotion, when the product is back at its regular price level. Investigations of uncertain promotions have focused on the immediate benefits and have shown that GPDs might induce purchase incentives similar to comparable RPDs (e.g., Goldsmith and Amir 2010). However, no study has explored the consequences of GPDs for customers' IRPs and repurchasing subsequent to the promotion. The major purpose of our research is to compare gambled price discounts to regular price discounts with regard to customers' internal reference price and repurchase behavior subsequent to the promotion.

Price promotions involving uncertainty have become increasingly prevalent (Laran and Tsiros 2013). A prominent example is the Sears Super Scratch event, where customers receive a scratch-and-save card that grants them savings up to $\$ 500$. In this instance, the element of uncertainty is introduced by the cashier, who is required to scratch the card and reveal the discount to the customer after the purchased items are checked out. Recently, several U.S. retail chains have started to offer similar scratch-and-save promotions, where discounts are uncertain (Choi, Stanyer, and Kim 2010). Another example of GPDs is the "roll the dice” discount, where 
customers determine the saving by rolling the dice after their purchase has been registered. Several apparel chains (Jack Jones, Mustang Jeans) as well as fast-food stores (Hooters) have recently conducted such "roll the dice” GPD campaigns.

With the advent of uncertain promotions, marketing research has started to investigate benefits associated with this innovative type of promotion. Prior work has particularly focused on how uncertainty affects customers’ induced purchase incentive (Dhar, González-Vallejo, and Soman 1995; Goldsmith and Amir 2010). An interesting finding in this respect is that customers perceive promotions involving uncertainty to be as attractive as regular promotions when it comes to inducing trial (Goldsmith and Amir 2010).

While research on uncertain promotions thus provides insight into promotion attractiveness and the immediate purchase intention (induced by the promotion), consequences for customers’ price perceptions and subsequent repurchase behavior (after the promotion has ended) have not been explored. However, a number of studies show that RPDs affect customers' immediate purchase intention and subsequent repurchase behavior. RPDs increase immediate purchase intention by providing a purchase incentive, but at the same time may reduce subsequent repurchasing by undermining customers’ price perceptions (Alba et al. 1994, 1999; Kalwani and Yim 1992; Diamond and Campbell 1989; Lattin and Bucklin 1989). Specifically, RPDs adversely affect subsequent repurchase behavior because they lower customers’ internal reference price (IRP), which serves as the primary comparison standard for judging the attractiveness of prices (Monroe 1973). This lowering of customers’ IRP, which we label the reference price effect, reduces repurchasing because after the promotion, consumers judge regular selling prices as less attractive than the lowered IRP (Mayhew and Winer 1992). Hence, while the RPD has the ability to induce trial, the corresponding reference price effect has strong implications for the effectiveness of price promotions. 
Against this background, the key proposition of the current research is that unlike RPDs, GPDs are not associated with lowered IRPs and thus do not generate the reference price effect but provide a level of purchase incentive similar to RPDs. We base our prediction for the differential effects of GPDs versus RPDs on IRPs and repurchasing on the diagnosticity concept (Feldman and Lynch 1988), which constitutes a central theoretical approach to explain individuals' use of information. We suggest that customers do not incorporate the GPD sale price into their IRP because they perceive it as atypical and uncertain and hence not diagnostic for typical price levels.

To compare the consequences of RPDs and GPDs for customers' IRP, we conducted five studies: two longitudinal field experiments and three scenario experiments (Figure 1 presents an overview of the conceptual framework and studies). The initial field experiment (Study 1) used a realistic setting to test our basic prediction that GPDs do not suffer from the negative reference price effect. It spanned three weeks and comprised a sample of 384 customers who could be tracked over the study's three measurement points. Study 2, a longitudinal field experiment similar to Study $1(\mathrm{n}=172)$, also used a realistic setting to test the differential effects of GPDs versus RPDs on customers’ actual repurchase behavior and examined the underlying psychological mechanisms. Studies 1 and 2 reveal that unlike RPDs, GPDs (much like a nodiscount control condition) do not reduce customers’ IRP and in fact lead to higher repurchasing than RPDs. We further show that the effects of GPDs and RPDs on customers' IRP result from differential processing of the price promotions in terms of perceived uncertainty and atypicality of the sale price. In Study 3, which comprised a scenario-based laboratory experiment $(\mathrm{n}=136)$, we assessed availability of a quality cue in the promotion as a boundary condition of the observed effects. Results show that the adverse reference price effect arising from RPDs as opposed to GPDs is most pronounced if no quality cue is available. Finally, two additional scenario-based 
laboratory studies show that our findings are robust to variations of GPD discount levels and winning probabilities as key GPD design parameters.

This research contributes three important insights to the literature. First, we address recent calls to explore customer reactions to uncertainty in promotions (Goldsmith and Amir 2010) and to assess the relative effectiveness of new price promotion methods (Darke and Chung 2005; Grewal et al. 2011). Second, we identify sale price atypicality and sale price uncertainty as the mechanisms explaining the differential effects of GPDs and RPDs. Third, we contribute to the literature on reference price formation, since the effect of price discounts involving uncertainty on reference price formation has not previously been investigated (Mazumdar, Raj, and Sinha 2005). Beyond having research implications, our results provide meaningful and actionable recommendations to firms that spend a major part of their promotional budget on price promotions (Ailawadi et al. 2007).

Insert Figure 1 about here

\section{Conceptual Framework}

In what follows, we describe the conceptual framework that constitutes the basis for our examination of the differential effects of GPDs and RPDs on IRPs and repurchasing behavior, as well as the underlying psychological mechanisms and boundary conditions.

\section{The Diagnosticity Concept}

The diagnosticity concept proposes that the likelihood that an individual will use an information cue as an input for a judgment increases with the perceived relevance of the information for the judgment (Feldman and Lynch 1988; Lynch, Marmorstein, and Weigold 1988). That is, the more useful the person perceives the information cue to be in accomplishing a judgment goal, the more 
diagnostic the respective cue is for the specific judgment task. The diagnosticity concept has been broadly applied in various domains of marketing research (e.g., Herr, Kardes, and Kim 1991; Miniard, Sirdeshmukh, and Innis 1992; Suk et al. 2010).

Whether someone perceives a cue as diagnostic (i.e., relevant) for a judgment task critically depends on characteristics of the cue (Feldman and Lynch 1988). Two central characteristics determining a cue's diagnosticity are (1) the uncertainty associated with the cue (Feldman and Lynch 1988; Hoch and Ha 1986; Skowronski and Carlston 1989) and (2) the atypicality (or dissimilarity) of the cue as compared to previously encountered cues (Feldman and Lynch 1988; Lynch, Marmorstein, and Weigold 1988).

Uncertainty and diagnosticity. The diagnosticity concept suggests that high uncertainty with regard to the actual realization of a cue's value decreases the cue's diagnosticity and hence its influence on the evaluation of a target object (Skowronski and Carlston 1989). Specifically, when forming judgments individuals discount uncertain cues and give them less weight since they provide unreliable information and might thus result in inaccurate impressions.

In our price promotion context, we focus on the uncertainty associated with the sale price offered in the promotion. Specifically, we understand sale price uncertainty to be the customer's perceived lack of knowledge with regard to the actual sale price resulting from the price promotion. On the basis of the diagnosticity concept, we argue that heightened levels of sale price uncertainty linked to GPDs reduce the diagnosticity of the GPD sale price and thus its influence on customers’ IRP formation.

Atypicality and diagnosticity. With regard to atypicality, individuals perceive cues that exhibit values different from previously encountered values as being atypical for a target (Feldman and Lynch 1988). That is, cues exhibiting low overlap with previously encountered information are seen as being unrelated and hence nondiagnostic for judging the target (Lien and 
Stayman 1998; Miniard, Sirdeshmuk, and Innis 1992), implying little influence of atypical cue realizations on judgment formation.

In transferring this notion to our price promotion context, we focus on the atypicality of the sale price offered in the price promotion in terms of discount size (e.g., Yadav and Seiders 1998; Gupta and Cooper 1992; Mobley, Bearden, and Teel 1988). In particular, we define sale price atypicality as the perceived discrepancy of the sale price from the price category that the customer regards as normal (Monroe 1971; Kopalle and Lindsey-Mullikin 2003). For GPDs, the sale price refers to the price promised to the customer for winning the price gamble. When the expected discount value for GPDs and RPDs is held constant, the GPD sale price displayed in the price promotion is substantially lower than the corresponding RPD sale price and should thus evoke stronger perceptions of sale price atypicality. We propose that increased sale price atypicality—which is characteristic of GPDs—reduces the diagnosticity of the GPD sale price and hence its impact on customers' IRP formation. Prior researchers note that "a large price reduction ... . may not be assimilated to affect the brand's expected price if it is considered exceptional” (Kalwani and Yim, 1992, p. 92).

\section{Hypotheses Development}

On the basis of the conceptual framework outlined above, we develop hypotheses on the differential effects of GPDs as compared to RPDs on customers' IRPs $\left(\mathrm{H}_{1}\right)$ and repurchase behavior $\left(\mathrm{H}_{3}\right)$. Furthermore, we derive predictions pertaining to sale price uncertainty $\left(\mathrm{H}_{2 \mathrm{a}}\right)$ and sale price atypicality $\left(\mathrm{H}_{2 \mathrm{~b}}\right)$ as the underlying psychological mechanisms and examine the availability of a quality cue $\left(\mathrm{H}_{4}\right)$ as a boundary condition. 


\section{Uncertainty, Diagnosticity, and the Reference Price Effect}

In what follows, we argue that the uncertainty associated with GPDs should lead to lower levels of diagnosticity and hence less impact of the GPD on customers' IRP, since cues associated with uncertainty provide ambiguous information.

Sale prices may influence customers' IRP because price promotions initiate a reasoning process on the part of the customer regarding appropriate price levels of an advertised product (Jacobson and Obermiller 1990; Raghubir 1998; Kwon, Schumann, and Fairhurst 2010). Whether customers use a particular sale price to adjust their IRP for a product depends on how usefulthat is, how diagnostic - the customer conceives the given price information to be in gaining an understanding of suitable price levels (Broniarczyk and Alba 1994; Yadav and Seiders 1998; Biswas and Blair 1991).

The degree of uncertainty associated with a particular sale price cue limits its perceived diagnosticity for price-related inferences (Feldman and Lynch 1988). In support of this notion, prior price promotion research has found that customers view tensile price claims as holding little informational value owing to the uncertainty linked with this promotion type (Mobley, Bearden, and Teel 1988). Low diagnosticity of a sale price should lead customers to refrain from using the price to adjust their IRP (Janiszewski and Lichtenstein 1999; Suk et al. 2010). Thus, owing to low perceived uncertainty, customers may adjust their IRP when encountering an RPD sale price, whereas they may refrain from doing so for GPDs, which entail a probabilistic component.

$\mathrm{H}_{1}$ : Customers' IRP after the price promotion is lower for RPDs than for GPDs and a nodiscount control condition.

$\mathrm{H}_{2 \mathrm{a}}$ : The differential effect of GPDs versus RPDs on customers' IRP is due to higher levels of GPD sale price uncertainty. 


\section{Atypicality, Diagnosticity, and the Reference Price Effect}

The individual perceives diagnosticity from the perspective of his or her judgment goals (Lynch, Marmorstein, and Weigold 1988). In IRP formation, the customer's goal is to form a typical representation of the product price. Typicality is an inherent characteristic of the IRP concept since forming a typical IRP is important to making well informed price judgments (Mazumdar, Raj, and Sinha 2005).

In light of customers' goal to form a typical IRP, whether the customer integrates the perceived sale price with the IRP should depend on the typicality of the sale price: the more atypical the sale price in terms of deviation from normal price levels, the lower its diagnosticity for forming a typical IRP and thus the lower the customer's propensity to change the IRP in response to perceiving the sale price (Yadav and Seiders 1998).

Relating GPDs and RPDs to sale price atypicality, we argue that GPD sale prices should be perceived as considerably more atypical than RPD sale prices. A GPD sale price refers to the advertised sale price that may be achieved if the customer wins the gamble. When the expected discount value for GPDs and RPDs is held constant, a realized GPD sale price is substantially lower than the corresponding RPD sale price and should thus evoke stronger perceptions of sale price atypicality. For instance, given a regular product price of $\$ 10$ and an average discount of $25 \%$ the RPD sale price is $\$ 7.50$, whereas the GPD sale price amounts to $\$ 5$ with a 50-50 chance, thus lying 33\% below the RPD sale price. The heightened levels of sale price atypicality induced by GPDs as compared to RPDs in turn render the GPD sale price less relevant- that is, nondiagnostic - for forming an IRP that is supposed to reflect typical price levels (Chandrashekaran and Grewal 2003; Kopalle and Lindsey-Mullikin 2003). Thus, high sale price atypicality associated with GPDs should deter customers from reducing their IRP. 
$\mathrm{H}_{2 \mathrm{~b}}$ : The differential effect of GPDs versus RPDs on customers' IRP is due to higher levels of GPD sale price atypicality.

\section{Linking GPDs and RPDs to Customer Repurchase Behavior}

Transaction utility describes customers’ perception of the financial attractiveness of a deal (Thaler 1985). Customers determine deal attractiveness through a mental comparison of the product's selling price and their IRP for the product: the lower the customer's IRP, the less attractive an actual price and the lower the likelihood of purchasing the product. Since we predict RPDs to lower customers’ IRPs as opposed to GPDs and the no-discount control condition, customers in the RPD condition may view the promoted product as overpriced once the product price returns to its regular level. Hence, they may refrain from repurchasing the promoted item, whereas this should not be the case for the GPD and no-discount control conditions, in which IRPs remain unaltered.

This reasoning is supported by prior research on reference prices. A well established empirical generalization states that customers’ purchase intention increases with an increasing reference price (Kalyanaram and Winer 1995; Mazumdar, Raj, and Sinha 2005; Winer 1986 refers to this observation as the "sticker shock" effect). Recent research has demonstrated that customers' comparison of IRPs with perceived selling prices influences their purchase decision (Saini, Rao, and Monga 2010). On the basis of this evidence and our proposition that RPDs entail lower IRPs than GPDs and a no-discount control condition, we conclude:

$\mathrm{H}_{3}$ : Customers' likelihood of repurchasing the promoted product after the treatment is higher for GPDs and the no-discount control condition than for RPDs.

\section{Availability of a Quality Cue as a Boundary Condition}

The diagnosticity concept predicts that the diagnosticity individuals attach to a focal cue is inversely related to the diagnosticity of alternative cues that are relevant to the judgment (Lynch 2006). That is, the higher the perceived relevance of a certain cue for a judgment, the lower the 
perceived relevance of an alternative cue. Apart from sale price information, a quality cue included in the price promotion may constitute a highly potent and relevant cue to customers as to whether they should adjust their IRP (Darke and Chung 2005; Mazumdar, Raj, and Sinha 2005). This relevance may occur because quality cues assure customers of a product's value, making adaptions of the IRP based on the sale price information less likely. Supporting this notion, prior behavioral pricing research shows that perceived quality constitutes an important factor in IRP formation and is positively associated with customers' IRP (Grewal, Monroe, and Krishnan 1998). Owing to the high diagnosticity of quality cues for IRPs, we suggest that if the price promotion includes a quality cue (such as a third-party evaluation), the perceived RPD sale price is rendered less diagnostic for IRP formation. Consequently, the RPD sale price may be less important as an information input to customers’ IRP formation. Thus, we propose:

$\mathrm{H}_{4}$ : The negative effect of RPDs as compared to GPDs and a no-discount control on customers' IRP is less pronounced if a quality cue is provided with the price promotion.

\section{Study 1: Field Experiment—Do GPDs Suffer from the Reference Price Effect?}

\section{Method}

To test the effect of GPDs on customers’ IRP, we conducted a large-scale field experiment over three weeks, in three stores of a local fast-food chain that cooperated with us. The stores are situated in densely populated urban areas in the vicinity of working places and shopping facilities. Therefore, a large number of customers regularly frequent these fast-food stores to have lunch. The stores are geographically separated, which is important to prevent a diffusion of the treatment. In addition, sales and customer composition are similar for the three stores. 
Experimental design. To test our hypotheses, we used a three-group pretest-posttest design in a naturalistic setting. We manipulated the type of price promotion that has been run for a specific type of fast-food meal. The meal was identical throughout the experiment and across the fast-food stores. Specifically, one store ran an RPD, while another store ran a GPD and the third store was used as a control group. The data obtained in the first week served as a premeasure, while the treatment was carried out throughout the second week. We gathered data in the second week as a post-treatment measurement, as well as in the third week to check whether the treatment had lasting effects. Thus, our data contain three measurement points, which are denoted consecutively as $t_{1}$ (first week), $t_{2}$ (second week), and $t_{3}$ (third week).

During the three weeks of the field experiment, we intercepted customers in the stores and asked them to complete a questionnaire on price and promotion perceptions and to provide demographics. To conduct the study, we recruited a data collection team composed of students. To intercept the customers, the data collection team was on site during all hours of operation. The team was informed about the operational procedures of the experiment, but received no information on the hypotheses to avoid demand effects. The study included only customers who purchased the meal. During all measurement periods, the data collection team inquired whether the customer had purchased the fast-food meal that we focused on in the study. If the customer answered this initial question affirmatively, the research assistants asked the customer to participate in the survey. In week 1, we intercepted every fifth customer, while in week 2 and week 3 we intercepted all customers. As gratification for participation in the study, we offered a free dessert. As customers were not randomly assigned to each fast-food store and price promotion type, the design of the study classifies as quasi-experimental.

To track the individual responses over the three weeks, we used an individual ID code for each participant. Customers indicated the code when filling out the questionnaire. Specifically, 
we asked them to use the first two letters of their mother's given name, the first two letters of their father's given name, and the last two digits of their own birthdate, resulting in an individual identification code. Throughout the three weeks, each time a customer answered a questionnaire, we asked the customer to provide the identification code. We then used this code to link customers' responses over the observation period.

Sample description. The data set of Study 1 comprises customer responses that we could match over the three measurement periods of the field experiment. We were able to track responses from 384 customers for all three measurement periods of the study, allowing for a within-subjects design (RPD store: 115 customers, GPD store: 121 customers, control store: 148 customers). This sample permits us to analyze changes in each customer's IRP induced by the different price promotion formats.

Price promotion manipulation. The fast-food meal we chose as a stimulus was sold at a regular price of $2 €$. The specific meal we selected fulfilled several criteria, which were important for achieving the goal of our study. It was sold identically in the three sample stores and the product sales were sufficiently high to yield an adequate sample size.

Inherent to the lottery mechanism of GPDs is that the discount for each customer is different depending on whether he or she wins the gamble. To be able to compare GPDs with RPDs, we held the average discount constant between the two conditions. Consistent with prior research, we used an average discount of 25\% (Grewal, Marmorstein, and Sharma 1996; Tsiros and Hardesty 2010). The regular price for the fast food was $2 €$. For the RPD with a discount of $25 \%$, the sale price was $1.50 €$. To inject an element of uncertainty for the GPD, we developed a lottery mechanism with a $50 \%$ chance for a sale price of $1 €$ and a $50 \%$ chance for the full price of $2 €$ (the average discount was again $25 \%$ ). We created a simple dice gamble that granted the customers a sale price of $1 €$ if the result was 4,5 , or 6 , whereas the customer paid the regular full 
price of $2 €$ if the result was 1,2 , or 3 . We conducted a pre-test with students $(n=43)$ to assess whether the incentive to purchase was similar for the RPD and GPD conditions using the item “The price promotion induces me to buy the fast-food meal” (strongly agree/disagree). Comparison of the conditions with regard to the induced purchase incentive revealed that the two treatments resulted in similar initial purchase incentives for the product $\left(\mathrm{t}(41)=.49, \mathrm{~ns} ; \mathrm{M}_{\mathrm{GPD}}=\right.$ 3.82, $\left.\mathrm{M}_{\mathrm{RPD}}=3.96\right)$.

We took care that the operational procedures of the two price promotions were identical. We had advertisements printed and located inside the stores, and store employees handed flyers to the customers inside as well as outside the store. The store managers assured us that this is a common practice for price promotions in that business. For the RPD condition, the advertisements and flyers stated, “Today’s Price Promotion - Pay $1.50 €$ instead of $2 €$ ” (with the $2 €$ crossed out). For the GPD condition, the advertisements and the flyers stated, “Today’s Price Promotion - Toss the dice with a $50 \%$ chance to pay $1 €$ instead of $2 €$ ” (with the $2 €$ crossed out). In the control store, no price promotion was conducted, no flyers were distributed, and the regular prices and products were advertised as usual.

In the treatment week $\left(\mathrm{t}_{2}\right)$, after entering the GPD or RPD store, customers were exposed to advertisements placed in their field of vision and were handed a price promotion flyer by an employee. Customers then made a purchase decision, moved to the food counter, and ordered the meal. They then received the meal on a food tray and moved to the checkout counter. Customers in the RPD condition who decided for the promoted meal were charged the sale price of $1.5 €$ at the checkout counter. In the GPD condition, customers who decided for the promoted meal were invited to toss the dice to determine the price discount prior to paying at the checkout counter. The customer then paid either $1 €$ or $2 €$, depending on the result. We intercepted the customers as they were leaving the store. 
Measures. The measurement of the IRP was based on operationalizations from prior works that highlight the need to capture customers' IRP on multiple dimensions (Grewal, Monroe, and Krishnan 1998; Lichtenstein, Burton, and Karson 1991). Participants were asked to provide the average market price and a fair price for the fast-food meal in euros. Our measurement approach is in line with studies showing that customers form product-specific reference prices (Briesch et al. 1997; Rajendran and Tellis 1994). The scales used for measuring IRP, quality perception, and shopping frequency are detailed in the Appendix. All scale reliabilities exceed the threshold of $.7\left(\alpha_{\mathrm{IRP}}=.74, \alpha_{\text {Quality perception }}=.90\right)$. Table 1 provides an overview of descriptive statistics of Study 1.

Insert Table 1 about here

\section{Results}

Validity checks. Before testing the hypotheses, we performed several validity checks. Specifically, we checked whether the three experimental conditions were comparable with regard to key variables (gender, age, deal attractiveness, and attention) and whether the dependent variables were influenced by the outcome of the price gamble and sample composition. Results showed that no selection bias existed (see Table 2).

Insert Table 2 about here

Hypotheses testing approach. In Study 1, participants were linked over the study’s three measurement points, allowing for a longitudinal structural equation modeling approach accounting for changes of customers' IRP over time. The longitudinal model comprises a causal chain linking the price promotion treatment in $t_{2}$ to customers' IRP in $t_{2}$ and IRP in $t_{3}$ (see Figure 1). For $\mathrm{H}_{1}$, we focused on the effect of the price promotion treatment on $\operatorname{IRP}_{\mathrm{t} 2}$ while controlling for $\mathrm{IRP}_{\mathrm{t} 1}$ to partial out the treatment effect. To incorporate the experimental treatment into the model, we coded two binary dummy variables (Bagozzi and Yi 1989). The dummy variables 
represent our three experimental groups, where RPD was selected as the reference group (coded as 0 in both dummies). We include customers' shopping frequency and quality perceptions as covariates in the model estimation.

Hypotheses tests. We estimated the proposed models employing Mplus 7 (Muthén and Muthén 2010). The model fits the data well (CFI = .96; $\left.\chi^{2}(\mathrm{df})=18.8(5) ; \mathrm{SRMR}=.03\right)$. Results confirm our hypotheses and show that GPDs and RPDs influence customers’ IRP as expected (see Table 3). In line with $\mathrm{H}_{1}$, the effect of the dummy variable RPD versus GPD shows that $\operatorname{IRP}_{\mathrm{t} 2}$ (after the treatment) for RPDs is significantly lower than for GPDs $(\beta=.20, p<.01)$. Moreover, the effect of the dummy variable comparing the RPD with the no-discount control condition (with control coded as 1 ) is positive and significant $\left(\beta=.17, p<.01\right.$ ), corroborating $\mathrm{H}_{1}$. Providing further support, the IRP mean values for the GPD and no-discount control condition do not differ significantly $\left(\mathrm{M}_{\mathrm{IRP} G P D}=2.20\right.$ vs. $\mathrm{M}_{\mathrm{IRP} \text { Control }}=2.18, \Delta \mathrm{M}=.02, \mathrm{t}=.637$, ns $)$. Results show that customers' IRPs decrease in response to RPDs, whereas IRPs remain unaltered for GPDs and the control condition. Table 4 depicts the pattern of IRP means.

Insert Table 3 about here Insert Table 4 about here

\section{Discussion of Study 1}

Study 1 provides support for our prediction that GPDs do not induce the reference price effect, which is often associated with RPDs. We find that customers' IRP is significantly lower in the RPD than in the GPD and no-discount control conditions, whereas no significant IRP difference occurs between GPDs and the control group. Study 2 is designed to probe more deeply into the underlying psychological mechanisms and analyze the consequences for customers’ repurchasing behavior. 


\section{Study 2: Field Experiment—Psychological Mechanisms and Repurchasing Behavior}

Having established that GPDs do not lower customers’ IRP as RPDs do, through Study 2 we extended Study 1 in two important ways. First, Study 2 examined the psychological mechanisms underlying the diverging effects of both promotion types on customers' IRP. Drawing on the diagnosticity concept, we argue that the perceived sale price atypicality and sale price uncertainty inherent to GPDs may be responsible for the absence of the reference price effect in the case of GPDs $\left(\mathrm{H}_{2 \mathrm{a}}, \mathrm{H}_{2 \mathrm{~b}}\right)$. Second, we analyze whether the differential effects of RPDs versus GPDs on customers’ IRP manifest in customer repurchasing behavior. To achieve these goals, we conducted a second field experiment in which we tracked actual customer repurchasing behavior and assessed price and promotion perceptions as well as the psychological mechanisms.

\section{Method}

Experimental design and procedure. The experimental design and procedure were identical to Study 1 . We again employed three stores of a fast-food chain to implement the promotion treatments (GPD, RPD, control) in a field setting. Thus, one store ran a GPD price promotion, one store ran an RPD promotion, and one store served as the no-discount control condition. As in Study 1, we used a within-subjects design, tracking customers’ IRP perceptions and shopping behavior over three measurement points: a pre-treatment measurement, a post-treatment measurement immediately after the price promotion treatment, and a second post-treatment measurement covering a period of three weeks after the price promotions to assess eventual repurchasing. The price promotions focused on one specific meal that is identically sold across the three stores of the chain. 
The field experiment lasted for five weeks. In the first week, we conducted a premeasurement where we surveyed customers of each store regarding their IRP, demographics, and shopping habits. In week 2, we implemented the price promotion treatment in the stores and surveyed customers who had purchased the focal meal during the price promotion phase after paying and leaving the cashier. The survey items addressed IRP, perceived sale price uncertainty, sale price atypicality, and perceptions of the promotion. In the three weeks following the treatment, we tracked for each condition whether customers who participated in both the premeasurement and the treatment week $\left(\mathrm{t}_{1}\right.$ and $\left.\mathrm{t}_{2}\right)$ repurchased the previously promoted meal. Specifically, we approached all customers of each fast-food store with a very short questionnaire directly after they had made their purchase and left the check-out. This procedure enabled our data collection team to observe and track whether customers had purchased the focal meal during the visit. As for Study 1, the design classifies as quasi-experimental because customers were not randomly assigned to the fast food stores.

Sample description. Our sample comprised data of 172 customers who could be tracked over the field experiment's pre-treatment measurement $\left(\mathrm{t}_{1}\right)$ and second measurement after the price promotion $\left(t_{2}\right)$. These customers constitute the basis for the assessment of the subsequent repurchase behavior. In the weeks after the price promotions, we tracked how many of those 172 customers who participated in both $t_{1}$ and $t_{2}$ repurchased the previously promoted product. Repurchasing occurred if customers purchased the previously promoted meal at least once during this three-week observation period. The GPD condition contained 67 participants, the RPD condition 65 participants, and the control condition 40 participants who could be tracked over the pre-treatment measurement period and the measurement after the promotion treatment. To track the individual responses over the measurement stages, we again used an individual ID code for 
each participant (see Study 1 for a detailed description), which customers indicated when filling out the questionnaire. The average age of participants was 28.2 years and $49 \%$ were male.

Price promotion manipulation. For the experimental treatments, we followed the same procedure as in Study 1. The fast-food meal we chose as a stimulus was sold at a regular price of 2.20€. Consistent with prior research, we used an average discount of 25\% (Grewal, Marmorstein, and Sharma 1996; Tsiros and Hardesty 2010). For the RPD with a discount of 25\%, the sale price was $1.65 €$. As in Study 1, we relied on a dice gamble to introduce an element of uncertainty for the GPD. Customers received a sale price of $1.10 €$ if the result was 4, 5, or 6 but paid the regular full price of $2.20 €$ if the result was 1 , 2, or 3 .

As in Study 1, we took great care that the operational procedures of the two price promotions were identical. We had advertisements printed and located inside the stores, and store employees handed flyers to the customers inside as well as outside the store. For the RPD condition, the advertisements and flyers stated, “Today’s Price Promotion - Pay 1.65€ instead of 2.20€” (with the 2.20€ crossed out). For the GPD condition, the advertisements and the flyers stated, “Today’s Price Promotion - Toss the dice and with a 50\% chance pay $1.10 €$ instead of $2.20 € ”$ (with the $2.20 €$ crossed out).

Measures. We used the same measure as in Study 1 to assess customers' IRP (measured in euros; the Appendix presents details on all measures). Sale price uncertainty is operationalized based on the study of Laran and Tsiros (2013) and the measure of sale price atypicality is based on Monroe (1971). All scale reliabilities exceed the threshold of .7 $\left(\alpha_{\mathrm{IRP}}=.79\right.$, $\alpha_{\text {Sale Price Uncertainty }}=$ $\left..78 ; \alpha_{\text {Sale Price Atypicalty }}=.87\right)$.

Customers' actual repurchase behavior, which is the key dependent variable in this study, was operationalized as a dummy variable coded as 1 if the customer repurchased in the three 
weeks after the price promotion and 0 if the customer did not repurchase. Table 5 provides an overview of the key statistics of Study 2.

Insert Table 5 about here

\section{Results}

Validity checks. We find that results regarding customers' IRP in Study 2 mirror the findings from Study 1 (see Table 4). We conducted the same validity checks as in Study 1, and results confirm that GPDs and RPDs are equally salient and attractive, and IRPs as well as repurchase behavior are not significantly influenced by the outcome of the price gamble and sample composition (see Table 2). In sum, these checks provide evidence for the validity of our data and results.

Psychological mechanisms of GPDs versus RPDs $\left(H_{2 a, b}\right)$. We predicted that the differential effect on customers' IRP in $t_{2}$ (controlled for $t_{1}$ ) is mediated by sale price uncertainty and sale price atypicality. To assess mediation, we apply bias-corrected bootstrapping as recommended by Preacher and Hayes (2008). We specify the mediation model as follows: the model comprises the price promotion treatment variable (GPD (1) vs. RPD (0)) as the independent variable that affects the mediators sale price atypicality and sale price uncertainty, which in turn influence IRP as the dependent variable. Following Preacher and Hayes (2008), we simultaneously assess in one mediation model the direct effect of the price promotion treatment on IRP as well as the indirect effects of the price promotion treatment on IRP via sale price atypicality/uncertainty. Applying a bootstrapping approach, we derive confidence intervals (CI) for the direct and indirect effects based on bias-corrected estimates and 5,000 resamples.

Results of the mediation analyses provide support for our predictions (unstandardized path coefficients are shown; see Preacher and Hayes 2008). The price promotion treatment effect (with GPD coded as 1 ) on sale price uncertainty is positive and significant $\left(\mathrm{b}_{\mathrm{GPDversusRPD}_{\rightarrow} \text { Uncertainty }}\right.$ 
$=.825, p<.01 \mathrm{CI}_{99 \% \text { lower }}=.230, \mathrm{CI}_{99 \%}$ upper $\left.=1.447\right)$ and the subsequent effect of sale price uncertainty on IRP is positive and significant $\left(\mathrm{b}_{\text {Uncertainty } \rightarrow \mathrm{IRP}}=.041, p<.01 ; \mathrm{CI}_{99 \% \text { lower }}=.003\right.$, $\mathrm{CI}_{99 \%}$ upper $=.083$ ). The indirect effect of the price promotion treatment (GPD vs. RPD) via sale

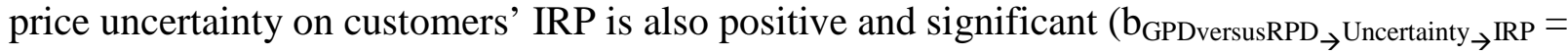
$.034, p<.01 ; \mathrm{CI}_{99 \% \text { lower }}=.004, \mathrm{CI}_{99 \%}$ upper $=.089$ ), corroborating $\mathrm{H}_{2 \mathrm{a}}$.

Likewise, the effect of the price promotion treatment on sale price atypicality is positive and significant $\left(\mathrm{b}_{\mathrm{GPDversusRPD}} \rightarrow\right.$ Atypicality $=.566, p<.05$; $_{95 \% \text { lower }}=.103, \mathrm{CI}_{95 \%}$ upper $\left.=1.027\right)$, as is the effect of sale price atypicality on IRP $\left(\mathrm{b}_{\text {Atypicality } \rightarrow \mathrm{IRP}}=.043, p<.05\right.$ CI $_{95 \% \text { lower }}=.001, \mathrm{CI}_{95 \%}$ upper $=.090)$. Also, the indirect effect of the price promotion treatment on IRP via sale price

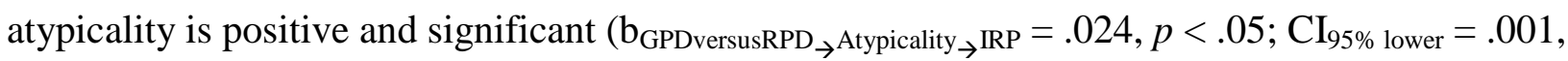
$\mathrm{CI}_{95 \%}$ upper $\left.=.081\right)$, supporting $\mathrm{H}_{2 \mathrm{~b}}$. Since the direct treatment effect on IRP is nonsignificant ( $\mathrm{b}=$ .095 , ns; $\mathrm{CI}_{95 \% \text { lower }}=-.001, \mathrm{CI}_{95 \% \text { upper }}=.193$ ), sale price atypicality and sale price uncertainty fully mediate the differential effect of GPDs versus RPDs on customers’ IRP.

Consequences for actual repurchase behavior $\left(H_{3}\right)$. Results show that compared to the GPD and no-discount control condition, the number of customers who repurchased the fast-food meal in the RPD condition is significantly lower. While in the GPD condition 70.1\% (72.5\% in the no-discount control condition) of customers who participated in the price promotion actually repurchased the meal in the three weeks after the price promotion, only 53.8\% of customers in the RPD condition did so $\left(\Delta \mathrm{GPD}\right.$ vs. RPD: $\left.\chi^{2}(1,131)=3.727, p<.05\right)$. A logistic regression reveals that the likelihood that a customer from the GPD condition repurchases is significantly higher than in the RPD condition ( $\mathrm{b}=.163, p<.05)$. Moreover, the percentage of customers repurchasing in the RPD condition is significantly lower than in the control condition ( $\triangle \mathrm{RPD}$ vs. control: $\left.\chi^{2}(1,104)=3.620, p<.05\right)$, whereas the percentage of those repurchasing per treatment 
group does not substantially differ between the GPD and control conditions ( $\triangle$ GPD vs. control: $\left.\chi^{2}(1,106)=.0627, \mathrm{~ns}\right)$. Thus, $\mathrm{H}_{3}$ is supported.

\section{Discussion of Study 2}

We developed Study 2 with two primary purposes in mind. Our first objective was to explore the psychological mechanisms responsible for the differential effects of RPDs versus GPDs on customer perceptions. Our second goal was to examine whether the reference price effect evoked by RPDs manifests in customers’ actual repurchase behavior once the product price is restored to its regular level. Regarding the first goal, we found support for our prediction that GPDs induce significantly higher levels of sale price uncertainty and sale price atypicality, leading customers to not use this information to change (i.e., lower) their IRP in response to GPDs. With respect to the second goal, Study 2 reveals that customers in the GPD condition are more likely to repurchase the promoted item after the promotion has ended than are customers in the RPD condition. Moreover, customers’ actual repurchasing after the promotions does not differ between the GPD and control conditions.

\section{Study 3: Availability of a Quality Cue as a Boundary Condition}

In a third study, we tested whether the differential effects of GPDs versus RPDs on IRPs are contingent on the availability of additional price-related information. In $\mathrm{H}_{4}$, we predicted that the negative effect of RPDs as compared to GPDs and a no-discount control on customers' IRP is attenuated if additional price-related information, such as a quality cue, is provided with the price promotion. To verify this prediction, we conducted a scenario experiment in which we manipulated price promotion type and availability of a quality cue. 


\section{Method}

Stimuli and experimental design. We randomly assigned 136 undergraduate students (55\% female; mean age, 24 years) to one of six conditions in a 3 (GPD, RPD, control) x 2 (quality cue available/not available) between-subjects design. To render the scenarios highly realistic to the participants, we simulated the purchase of a coffee at a café that is conducting a promotion. The stimulus in this scenario was an advertisement for a cappuccino. Depending on the experimental group, the advertisement was a GPD price promotion, an RPD price promotion, or for the control group, an advertisement without any price reduction. Availability of a quality cue was manipulated by adding a third-party quality label to the advertisement in the perceived highquality condition and not adding a quality label in the low-quality condition.

Procedure. Participants were told that they were looking for a cup of coffee in a coffee bar. In the scenario, we stated that the coffee bar was currently running a promotion for cappuccino. Participants were invited to look at the promotion advertisement, which we used to manipulate the price promotion format (Goldsmith and Amir 2010; Winterich and Barone 2011). The ad contained a picture of the cappuccino and information regarding the cappuccino and the price promotion.

As in Studies 1 and 2, we used an average discount of 25\% in the RPD and GPD conditions to hold the expected benefit constant (Grewal, Marmorstein, and Sharma 1996; Tsiros and Hardesty 2010). The RPD ad said, "Price Promotion - Was $4 €$ (with the four crossed out), now 3.00€," while the GPD ad said, "Price Promotion - Was $4 €$ (with the four crossed out), now toss the dice and with a 4, 5, or 6 pay 2.00€.” The control condition comprised an advertisement for the cappuccino indicating its regular price. We manipulated the availability of a quality cue by adding a third-party quality label to the advertisement in one condition and no quality label in the other condition. After viewing the promotion ad, we asked participants to provide their IRPs 
(in euros) and perceptions related to the price promotions. To assess customers' IRP, which is the dependent variable in this study, and product quality perceptions, we used the same measures as in the previous studies.

\section{Results and Discussion}

To examine whether the availability of a quality cue interacts with the promotion treatments, we ran an ANOVA with the promotion treatment factor (GPD, RPD, control) and availability of a quality cue (available, not available) as the independent variables and IRP as the dependent variable. As a first step, we verified that the manipulation of perceived quality worked as intended: participants perceived a significantly higher level of quality if a quality cue was present than if no cue was included in the price promotion ad $\left(\mathrm{M}_{\text {quality cue }}=4.83, \mathrm{M}_{\text {no quality cue }}=4.22, \mathrm{t}=\right.$ 2.899, $p<.01)$.

Results of the ANOVA show that the negative effect of RPDs on the IRP, as compared to the effect of GPDs, is less pronounced if a quality cue is available, confirming $\mathrm{H}_{4}$. Both the price promotion treatment $(\mathrm{F}(2,130)=3.301, p<.05)$ and the availability of a quality cue $(\mathrm{F}(1,130)=$ 5.709, $p<.05$ ) exert significant main effects on customers' IRP. Moreover, the treatment factors exhibit a significant interaction effect $(F(2,130)=3.336, p<.05)$. Figure 2 illustrates the pattern of results. Confirming $\mathrm{H}_{4}$, if a quality cue is provided as additional price-related information, no significant differences exist in the IRP levels of the RPD, GPD, and control conditions (mean IRP for high-quality condition: $\mathrm{M}_{\mathrm{GPD}}=2.96$ vs. $\mathrm{M}_{\mathrm{RPD}}=2.98 ; \mathrm{M}_{\mathrm{Control}}=3.00 ; \mathrm{F}(2,130)=.039$, ns). However, the IRP difference between GPDs and RPDs is most pronounced if no quality cue is present (mean IRP for the low-quality condition: $\mathrm{M}_{\mathrm{GPD}}=2.89$ vs. $\mathrm{M}_{\mathrm{RPD}}=2.49 ; \mathrm{F}(1,130)=$ 5.978, $p<.01$ ), while the IRP level in the no-discount control condition does not differ significantly from the GPD condition (mean IRP for low-quality condition: $\mathrm{M}_{\mathrm{GPD}}=2.89$ vs. $\mathrm{M}_{\text {Control }}=2.96 ; \mathrm{F}(1,130)=.303$, ns) but is significantly higher than in the RPD condition (mean 
IRP for the low-quality condition: $\mathrm{M}_{\mathrm{RPD}}=2.49$ vs. $\left.\mathrm{M}_{\text {Control }}=2.96 ; \mathrm{F}(1,130)=10.996, p<.01\right)$. These results show that if customers can rely on other (potentially diagnostic) price-related information beyond the sale price, the negative reference price effect of RPDs as compared to GPDs is less pronounced.

Insert Figure 2 about here

\section{GPD Design Parameters: Examining Varying Levels of GPD Discount and Uncertainty}

The level of discount provided to the customer and the uncertainty (in terms of winning probability) associated with GPDs constitute key design parameters of this price promotion type. We conducted two scenario-based laboratory experiments in which we assessed the robustness of our findings for different configurations of these design parameters of GPDs. In what follows, we first report an experiment in which we examined an alternative GPD operationalization with varied discount levels and then discuss an experiment in which we manipulated the level of uncertainty related to the GPD. Results show that our results pertaining to the differential effects of GPDs versus RPDs on IRP are robust to variations of these GPD design parameters.

\section{Varying GPD Discount Levels}

In the previous studies, we employed a GPD operationalization in which customers received a specified discount if they won a gamble but got no discount if they lost the gamble. To test the robustness of our findings for a different GPD operationalization, we altered the GPD discount levels so that customers who lost the gamble still received a discount. Specifically, we compare our initial operationalization of the GPD (50\% probability of no discount; $50 \%$ probability of $50 \%$ discount) to an operationalization with an equal expected value where customers received a discount in any case (50\% probability of 5\% discount; 50\% probability of $45 \%$ discount). We 
label this alternative operationalization GPD with a non-zero discount $\left(\mathrm{GPD}_{\mathrm{nz}}\right)$. Specifically, our objective in this study is to verify that a $G_{P D}$, like a GPD, does not suffer from the negative reference price effect as RPDs do.

\section{Method}

Stimuli and experimental design. Using a between-subjects design, we randomly assigned 166 undergraduate students (58\% female, mean age, 24.04 years) to four experimental conditions $\left(G P D, G P D_{n z}, R P D\right.$, and no-discount control). Participants were told that they were looking for a slice of pizza and were considering a purchase at a take-away pizza parlor. Subsequently, we manipulated the price promotion format by showing them a price promotion advertisement containing a picture of the slice of pizza and information regarding the pizza and the price promotion.

As in Study 1, we used an average discount of 25\% in the RPD and GPD conditions (Grewal, Marmorstein, and Sharma 1996; Tsiros and Hardesty 2010). The GPD $_{\mathrm{nz}}$ condition comprised a non-zero discount of $5 \%$ in the case of losing the gamble and a discount of $45 \%$ if winning the gamble. The RPD ad said, "Price Promotion - Was $3 €$ (with the three crossed out), now 2.25€," while the GPD ad said, "Price Promotion - Was $3 €$ (with the three crossed out), now toss the dice and with a 4, 5, or 6 pay 1.50€.” The GPD $\mathrm{nz}$ said, "Price Promotion - Was $3 €$ (with the three crossed out), now toss the dice and with a 1,2 or 3 pay $2.85 €$ - with a 4,5 , or 6 pay 1.65€.” The control condition comprised an advertisement for the pizza slice that included its regular price without mentioning any price reduction. After participants had viewed the price promotion ad for the pizza slice, we asked them to provide their IRPs and perceptions related to the price promotions. To assess customers' IRP, which is the dependent variable in this study, we used the same measure as in the previous studies. 


\section{Results and Discussion}

Results show that GPD and GPD ${ }_{\mathrm{nz}}$ similarly affect customers' IRP. To assess the effect of varying GPD discount levels, we ran an ANOVA with the price promotion treatment factor (comprising the groups GPD, GPD $\mathrm{nz}_{\mathrm{nz}}$ RPD, and no-discount control) as the independent variables and IRP as the dependent variable. The price promotion treatment factor had a significant effect on customers' IRP $(F(3,163)=2.755, p<.05)$. The pattern of results supports our key proposition that GPDs do not lower customers' IRP and shows that this finding applies to both GPD operationalizations analogously. The mean IRP in the RPD condition is significantly lower than in both the GPD and the $\mathrm{GPD}_{\mathrm{nz}}$ conditions $\left(\mathrm{M}_{\mathrm{RPD}}=2.15, \mathrm{M}_{\mathrm{GPD}}=2.35, \mathrm{M}_{\mathrm{GPDNZ}}=2.44 ; \mathrm{F}_{\triangle \mathrm{M}}\right.$ $\left.\operatorname{GPDvsRPD}(1,163)=3.523, p<.05 ; \mathrm{F}_{\triangle \mathrm{M} \text { GPDNZvsRPD }}(1,163)=8.684, p<.01\right)$. Moreover, the mean IRP in the RPD condition is lower than in the no-discount control condition $\left(\mathrm{M}_{\mathrm{RPD}}=2.15\right.$, $\left.\mathrm{M}_{\text {Control }}=2.33 ; \mathrm{F}_{\Delta \mathrm{M} \text { ControlvsRPD }}(1,163)=4.052, p<.05\right)$, whereas IRPs in the GPD and $\mathrm{GPD}_{\mathrm{nz}}$ conditions do not differ significantly from the control $\left(\mathrm{M}_{\mathrm{Control}}=2.33, \mathrm{M}_{\mathrm{GPD}}=2.35, \mathrm{M}_{\mathrm{GPDNZ}}=\right.$ 2.44; $\left.\mathrm{F}_{\triangle \mathrm{M} \text { GPDvsControl }}(1,163)=.001, \mathrm{~ns} ; \mathrm{F}_{\Delta \mathrm{M} \text { GPD NZvSControl }}(1,163)=1.181, \mathrm{~ns}\right)$.

The key objective of this study was to test whether our findings regarding the differential effects of GPDs versus RPDs also hold for a different GPD operationalization with varying discount levels. In this experiment, we altered the initial mechanism where customers did not receive any discount if they lost the gamble and examined whether our results hold for a GPD mechanism in which customers obtain a discount even when losing the gamble (labeled GPD non-zero). Results of this study illustrate that the outcome pattern is not influenced by the variation of GPD discount levels. Specifically, we find that neither GPD nor GPD $\mathrm{D}_{\mathrm{nz}}$ suffers from the reference price effect (similar to the no-discount control condition), whereas for RPDs, customers adjust their IRP downward in response to the price promotion. 


\section{Varying Levels of GPD Uncertainty}

Beyond the discount level, uncertainty constitutes an additional design parameter of GPDs. Uncertainty results from the winning probability with which the discount is granted to the customer. We define GPD winning probability as the likelihood that the customer will obtain the sale price during a GPD price promotion. In what follows, we examine whether the GPD winning probability affects the impact of GPDs on customer IRP formation. To this end, we conducted a scenario experiment in which we manipulated GPD winning probability.

Stimuli and experimental design. We randomly assigned forty-three undergraduate students (58\% female; mean age, 23.9 years) to one of three conditions: a GPD with either a low, medium, or high winning probability. The stimulus in this scenario was an advertisement for a shampoo that is on the customer's shopping list. We manipulated GPD winning probability in the promotion advertisement by altering information on the likelihood of receiving the sale price.

Procedure. Participants were told that they are shopping at a local grocery store and that the store is currently running a promotion for shampoo. Participants were invited to look at the promotion advertisement, which contained a picture of the shampoo and information regarding the shampoo and the GPD price promotion.

The regular price for the shampoo was displayed as $3 €$ in the ad. We used a discount of 25\% (Grewal, Marmorstein, and Sharma 1996; Tsiros and Hardesty 2010), resulting in a sale price of $2.25 €$. GPD winning probability was manipulated by varying the results of the dice gamble required for receiving the sale price. Specifically, in the low winning probability condition, the chance to receive the sale price was indicated as 1 out of 6 (only if the toss is 6 ). In the medium winning probability condition, the chance was indicated to be 3 out of 6 (if the toss is 4,5 , or 6 ), and in the high winning probability condition, the chance was 5 out of 6 (if the toss is $2,3,4,5$, or 6$)$. 
Consequently, the GPD ad in the low winning probability condition said, "Price Promotion - Was $3 €$ (with the three crossed out), now toss the dice and with a 6 pay 2.25€.” For medium and high winning probability conditions, the description of the winning dice toss was adjusted accordingly in the ad. After viewing the promotion ad for the shampoo, we asked participants to provide their IRPs and perceptions related to the price promotions.

\section{Results and Discussion}

The manipulation of GPD winning probability worked as expected. Participants perceived a significantly higher likelihood of receiving the sale price in the high probability condition than in the medium and low probability conditions (Item: “The likelihood of receiving the sale price is very low (1)/very high (7) $\left(\mathrm{M}_{\text {low winning probability }}=1.22, \mathrm{M}_{\text {medium winning probability }}=2.92\right.$, $\mathrm{M}_{\text {high winning }}$

probability $=4.20, \Delta \mathrm{M}_{\text {low vs medium winning probability }}=1.70, \mathrm{p}<.01 ; \Delta \mathrm{M}_{\text {medium vs high winning probability }}=1.28, \mathrm{p}$ $<.01)$.

To examine whether GPD winning probability affects customers’ IRP, we ran an ANOVA with winning probability (low, medium, high) as the independent variable and IRP as the dependent variable. Results show that GPD winning probability does not significantly influence customers' IRP. The main effect of winning probability on IRP is not significant F(2, $40)=.092$, ns), showing that no substantial IRP mean differences exist between the low, medium, and high GPD winning probability (WP) conditions $\left(\mathrm{M}_{\mathrm{IRP} \text { low } \mathrm{WP}}=2.31, \mathrm{M}_{\mathrm{IRP} \text { medium WP }}=2.32\right.$, $\left.\mathrm{M}_{\mathrm{IRP} \text { high WP }}=2.36\right)$. This outcome further underlines that our findings on the role of GPDs for customers' IRP seem to be robust to changes in the specific GPD operationalization.

\section{General Discussion}

\section{Summary}

Although uncertain price promotions are becoming more and more prevalent, how uncertainty in price promotions affects customers’ price perceptions and repurchase behavior is only partially 
understood. Therefore, our primary research question concerned whether GPDs, where savings depend on a gamble, suffer from the reference price effect as RPDs do.

In this regard, results of Study 1 show that unlike RPDs, GPDs do not lower customers' IRP and hence do not evoke the reference price effect. Moreover, results of Study 2 show that these differences also affect customers’ repurchase behavior after the promotion has ended and the price has returned to its regular level: the likelihood that customers would repurchase the previously promoted product decreased in response to RPDs, while for GPDs and a no-discount control condition, the repurchase likelihood remained unaltered. Additionally, Study 2 revealed that in the case of GPDs, heightened levels of sale price uncertainty and atypicality underlie the differential effects of GPDs versus RPDs on customers’ IRP. Study 3 demonstrated that the difference in IRP levels between GPD and RPD is less pronounced if additional price-related information, such as a quality cue, is included in the promotion. Finally, two scenario experiments showed the robustness of our findings to variations of the GPD discount level and uncertainty (in terms of winning probability) as key GPD design parameters.

\section{Research Issues}

With our study, we contribute to two research streams: (1) benefits of uncertainty in promotions and (2) research on IRP formation in behavioral pricing. First, by analyzing the process of IRP formation, we demonstrate that the positive influence of uncertainty in promotions is not restricted to customers’ perceptions of promotion attractiveness (e.g., Dhar, González-Vallejo, and Soman 1999), but also applies to customers’ price perceptions and repurchase behavior after the promotion has ended.

By examining the psychological processes underlying the favorable effects of GPDs, we respond to recent calls to provide a more detailed account of the positive effects of uncertain promotions (Goldsmith and Amir 2010). Drawing on the diagnosticity concept, we derive a sale 
price uncertainty and a sale price atypicality path, which jointly account for the differential effects of the promotion types on customers' IRP. While the sale price atypicality concept is well established in price promotion research (Kopalle and Lindsey-Mullikin 2003; Chandrashekaran and Grewal 2003), applying the diagnosticity concept to customer sale price perceptions is rather novel. Given its useful theoretical predictions for the effects of GPDs in our conceptual framework, a fruitful approach may be to incorporate the diagnosticity concept in research on price promotions. Further adding to the literature on benefits of uncertain promotions, our findings suggest that customers may rationally discard information originating from promotions associated with uncertainty. While prior work predominantly explains the positive effects of uncertainty in terms of perceptual biases, our results can hardly be interpreted in terms of perceptual biases implying bounded rationality of customers. Rather, our findings are in accordance with a rational learning perspective (Bray and Kreps 1981), which suggests that customers might reasonably leave the IRP unaltered as a response to uncertainty in a price promotion. Uncertain price promotions provide relatively little reliable information relevant for IRP formation, making it rational not to incorporate them. Future research could further investigate how far reactions to price promotions can be linked to perceptual biases versus rational learning on the customer's part.

Second, our study provides important implications for research on reference price formation and behavioral pricing. Prior research notes a great "need to explore the cognitive and perceptual underpinnings of price impressions" (Alba et al. 1999, p. 112). We add to this literature by exploring the role of uncertainty in the formation of price impressions. Research in this field has studied how uncertainty in customers' IRP influences integration of external price information (e.g., Manoj and Menon 2007; Biswas and Blair 1991; Herr 1989; Mazumdar and Jun 1992). Specifically, past work has assessed whether customers more readily integrate 
advertised sale prices with their IRP if their IRP is imprecise and vague. This study is the first to show how uncertainty in the externally provided price information influences IRP formation. We find that uncertainty decouples the external price information from the IRP and thus the uncertain sale price receives less weight in customers’ IRP formation. However, if additional price-related information, such as a quality cue, is provided with the price promotion, for RPDs, similar to GPDs, the external sale price information does not strongly influence IRP.

While at a first glance the "discounting” of uncertain sale price information in IRP formation might seem intuitive, research on incidental price anchors renders this finding more controversial. Behavioral pricing research has demonstrated that irrelevant price anchors or even irrelevant non-price anchors might substantially affect price judgments (Nunes and Boatwright 2004; Ariely, Loewenstein, and Prelec 2003). In light of customers’ susceptibility to incidental anchors, a noteworthy finding is that in the context of uncertain price promotions, customers do not rely on the sale price for IRP formation but account for its uncertain nature.

Our work illustrates that GPDs may entail long-term benefits for companies in terms of customers' reference prices and repurchasing behavior. However, beyond these effects, further long-term benefits of GPDs are conceivable. For example, GPDs may be instrumental to the promotion of a brand's quality image in the long run. As GPDs do not reduce customers' IRPs, a reasonable assumption is that this effect translates to customers' quality perceptions, enabling firms to grant discounts without endangering their quality image. Additionally, if a company frequently deploys GPDs, the resulting experiential value may enhance customers’ purchase satisfaction and thus strengthen attitudinal loyalty.

\section{Limitations and Future Research Directions}

Despite their identified benefits, GPDs may be associated with pitfalls. For instance, if not set up correctly, GPDs may instigate opportunistic behavior of customers. In our studies, customers 
took part in the price gamble after having committed to the purchase. If the price gamble is not unambiguously regulated by the promoting company, customers could refuse to pay or pay and return the product later in the case of losing the gamble. The incentive to do so could increase with the absolute price of the product, which is why GPDs may be particularly suitable for lower priced products.

Another potential pitfall of GPDs relates to the discrimination of customers who win and lose the price gamble. Social comparison processes may lead customers who lose the gamble to feel disadvantaged as compared to those who win. While comparison should not constitute a major issue in the short term and for inexpensive products, if GPDs occur frequently and for expensive products, losing the gamble may lead customers to develop negative feelings toward the promoting company. Identifying firm remedy strategies for this issue represents a worthwhile task for future research on GPDs.

The outcome of a price gamble may also affect customers on an emotional level, for instance by arousing excitement, joy, or disappointment in the case of losing (Holbrook et al. 1984). Although we verified that our findings are not biased by customers' emotional responses to winning or losing the gamble, emotions still might influence aspects of customers' shopping behavior that we did not examine in our study. Assessing the consequences of winning or losing GPDs for various shopping behaviors constitutes an interesting and important research endeavor. For example, future research might investigate how GPDs affect customers’ immediate spending behavior: customers might increase their spending in the case of winning the GPD owing to a perceived increase in their available budget, as proposed by literature on windfall gains (Arkes et al. 1994).

Furthermore, an important point is that the extent to which RPDs, as compared to GPDs, reduce customers' IRP might be influenced by context factors. Besides the availability of 
additional price-related information such as a quality cue, familiarity with the product category and price levels and involvement may constitute additional boundary conditions of the observed effects. In addition, the effects of GPDs in our study may have been influenced by the chosen product categories, as the effectiveness of a sales promotion may depend on its fit with the promoted product category (Chandon, Wansink, and Laurent 2000). Future research could therefore examine effects of promotion-product category congruence in the context of GPDs.

Finally, although quality constitutes an important correlate of price, we do not explicitly analyze the effects of GPDs versus RPDs on perceived quality. While we expected and verified in additional analyses that the effects on IRPs translate to customers' quality perception, we view more systematic examination of the GPD-quality perception relationship to be important.

\section{Managerial Implications}

Price discounts are pervasive in today's retail stores and marketers often spend a large part of their budget on this promotional tool (Darke and Chung 2005). However, price discounts have drawbacks that pose a considerable threat to their effectiveness, as customers become accustomed to the lowered sale price - that is, they adjust their IRP downwards or may draw negative quality inferences from the price discount. For managers, both effects are undesirable since the customer judges the usual selling price or the product quality as less attractive once the promotion has ended. Our research offers a solution to this dilemma by showing that price discounts involving uncertainty alleviate these negative effects. Thus, managers might employ GPDs to increase the effectiveness of price promotions by inducing purchase without endangering future sales and risking negative customer reactions. Regarding RPDs, our results indicate that marketers who intend to employ this type of promotion might consider communicating additional price-related information such as quality labels, as this information prevents the customer from integrating the sale price information and thus alleviates the negative reference price effect for RPDs. 
Retailers are confronted with the challenge "to grow the top line while also preserving their bottom line” (Grewal et al. 2011, p. 43), especially as in retailing profit margins are often a mere 1\% of net sales (Ailawadi and Harlam 2004). Managers are therefore constantly searching for ways to maximize sales from a given marketing budget. The results of our study propose that GPDs might represent such a cost-efficient means, since (1) with the same discount, a higher level of customers' subsequent repurchasing can be maintained as compared to RPDs, and (2) negative effects following the promotion can be avoided, particularly with regard to customers' IRP. We hope that our work stimulates future research to gain a deeper understanding of the various facets of price discounts involving uncertainty. 


\section{REFERENCES}

Ailawadi, Kusum L. and Bari Harlam (2004), "An Empirical Analysis of the Determinants of Retail Margins: The Role of Store-Brand Share,” Journal of Marketing, 68 (1), 147-65.

— - - Jaques César, and David Trounce (2007), "Quantifying and Improving Promotion Effectiveness at CVS,” Marketing Science, 26 (4), 566-75.

Alba, Joseph W., Susan M. Broniarczyk, Terence A. Shimp, and Joel E. Urbany (1994), "The Influence of Prior Beliefs, Frequency Cues, and Magnitude Cues on Consumers' Perceptions of Comparative Price Data,” Journal of Consumer Research, 21 (September), 219-35.

, Carl F. Mela, Terence A. Shimp, and Joel E. Urbany (1999), "The Effect of Discount Frequency and Depth on Consumer Price Judgments,” Journal of Consumer Research, 26 (2), 99-114.

Ariely, Dan, George Loewenstein, and Drazen Prelec (2003), "Coherent Arbitrariness: Stable Demand Curves without Stable Preferences,” Quarterly Journal of Economics, 118 (1), 73-105.

Arkes, Hal R., Cynthia A. Joyner, Mark V. Pezzo, Jane Gradwohl Nash, Karen Siegel-Jacobs, and Eric Stone (1994), “The Psychology of Windfall Gains,” Organizational Behavior and Human Decision Processes, 59 (3), 331-47.

Bagozzi, Richard P. and Youjae Yi (1989), "On the Use of Structural Equation Models in Experimental Designs,” Journal of Marketing Research, 26 (3), 271-84. $127-40$.

Biswas, Abhijit and Edward Blair (1991), "Contextual Effects of Reference Prices in Retail Advertisements,” Journal of Marketing, 55 (July), 1-12.

Bray, Margaret and David M. Kreps (1981), "Rational Learning and Rational Expectations,” Stanford University Graduate School of Business Research Papier Series, No. 616, Stanford University.

Briesch, Richard A., Laksham Krishnamurthi, Tridib Mazumdar, and S. P. Raj (1997), "Comparative Analysis of Reference Price Models," Journal of Consumer Research, 24 (2), 202 14.

Broniarczyk, Susan M. and Joseph W. Alba (1994), "The Importance of the Brand in Brand Extension,” Journal of Marketing Research, 31(5), 214-28.

Choi, Sungchul, Mike Stanyer, and Moontae Kim (2010), "Consumer Responses to the Depth and Minimum Claimed Savings of "Scratch and Save (SAS)" Promotions," Psychology \& Marketing, 27 (8), 766-79.

Darke, Peter R. and Cindy M. Y. Chung (2005), "Effects of Pricing and Promotion on Consumer Perceptions: It Depends on How You Frame It,” Journal of Retailing, 81 (1), 35-47.

DelVecchio, Devon, H. Shanker Krishnan, and Daniel C. Smith (2007), "Cents or Percent? The Effects of Promotion Framing on Price Expectations and Choice," Journal of Marketing, 71 (3), $158-70$.

Dhar, Sanjay K., Claudia González-Vallejo, and Dilip Soman (1995), "Brand Promotions As a Lottery,” Marketing Letters, 6 (3), 221-33. 
and - (1999), "Modeling the Effects of Advertised Price Claims: Tensile Versus Precise Claims?,” Marketing Science, 18 (2), 154-77.

Diamond, William D. and Leland Campbell (1989), "The Framing of Sales Promotions: Effects on Reference Price Change,” Advances in Consumer Research, 16 (1), 241-47.

Feldman, Jack M. and John G. Lynch Jr. (1988), "Self-Generated Validity and Other Effects of Measurement on Belief, Attitude, Intention, and Behavior,” Journal of Applied Psychology, 73 (3), 421-35.

Goldsmith, Kelly and On Amir (2010), “Can Uncertainty Improve Promotions?,” Journal of Marketing Research, 47 (6), 1070-77.

Grewal, Dhruv, Kusum L. Ailawadi, Dinesh Gauri, Kevin Hall, Praveen Kopalle, and Jane R. Robertson (2011), “Innovations in Retail Pricing and Promotions,” Journal of Retailing, 87 (July, Supplement 1), 43-52.

-, Howard Marmorstein, and Arun Sharma (1996), "Communicating Price Information through Semantic Cues: The Moderating Effects of Situation and Discount Size,” Journal of Consumer Research, 23 (2), 148-55.

Kent B. Monroe, and R. Krishnan (1998), "The Effects of Price-Comparison Advertising on Buyers' Perceptions of Acquisition Value, Transaction Value and Behavioral Intentions," Journal of Marketing, 62 (2), 46-59.

Gupta, Sunil and Lee G. Cooper (1992), "The Discounting of Discounts and Promotion Thresholds,” Journal of Consumer Research, 19 (December), 401-11.

Herr, Paul M. (1989), “Priming Price: Prior Knowledge and Context Effects,” Journal of Consumer Research, 16, 67-75.

, Frank R. Kardes, and John Kim (1991), "Effects of Word-of-Mouth and ProductAttribute Information of Persuasion: An Accessibility-Diagnosticity Perspective,” Journal of Consumer Research, 17 (4), 454-62.

Hoch, Stephen J. and Young-Won Ha (1986), "Consumer Learning: Advertising and the Ambiguity of Product Experience,” Journal of Consumer Research, 13 (September), 221-33.

Holbrook, Morris B., Robert W. Chestnut, Terence A. Oliva, and Eric A. Greenleaf (1984), "Play as a Consumption Experience: The Roles of Emotions, Performance, and Personality in the Enjoyment of Games," Journal of Consumer Research, 11 (2), 728-39.

Jacobson, Robert and Carl Obermiller (1990), "The Formation of Expected Future Price: Reference Price for Forward-Looking Consumers,” Journal of Consumer Research, 16(March), $420-32$.

Janiszewski, Chris and Donald R. Lichtenstein (1999), "A Range Theory Account of Price Perception,” Journal of Consumer Research, 25 (4), 353-68.

Kalwani, Manohar U. and Chi Kin Yim (1992), "Consumer Price and Promotion Expectations: An Experimental Study,” Journal of Marketing Research, 29 (1), 90-100.

Kopalle, Praveen K. and Joan Lindsey-Mullikin (2003), "The Impact of External Reference Price on Consumer Price Expecatations,” Journal of Retailing, 79, 225-36. 
Kwon, Kyoung-Nan, David W. Schumann, and Ann Fairhurst (2010), “Consideration of an Expected Future Deal in Assessing the Value of a Present Deal: Forward-Looking Bargain Shopping,” Journal of Business Research, 63(1), 84-90.

Laran, Juliano and Michael Tsiros (2013), "An Investigation of the Effectiveness of Uncertainty in Marketing Promotions Involving Free Gifts,” Journal of Marketing, 77 (March), 112-23.

Lattin, James M. and Randolf E. Bucklin (1989), "Reference Effects of Price and Promotion on Brand Choice Behavior,” Journal of Marketing Research, 26 (3), 299-310.

Lichtenstein, Donald R., Scot Burton, and Eric J. Karson (1991), "The Effect of Semantic Cues on Consumer Perceptions of Reference Price Ads,” Journal of Consumer Research, 18 (3), 38091.

Lien, Nai-Hwa and Douglas M. Stayman (1998), "Memory-Based Judgments: The Roles of Information Typicality and Processing Ability," Advances in Consumer Research, 3, 94-99.

Lynch Jr., John G., Howard Marmorstein, and Michael F. Weigold (1988), "Choices from Sets Including Remembered Brands: Use of Recalled Attributes and Prior Overall Evaluations,” Journal of Consumer Research, 15 (2), 169-84.

(2006), "Accessibility-Diagnosticity and the Multiple Pathway Anchoring and Adjustment Model,” Journal of Consumer Research, 33 (1), 25-27.

Manoj, Thomas and Geeta Menon (2007), "When Internal Reference Price and Price Expectations Diverge: The Role of Confidence,” Journal of Marketing Research, 44 (3), 401409.

Mayhew, Glenne E. and Russell S. Winer (1992), “An Empirical Analysis of Internal and External Reference Prices Using Scanner Data," Journal of Consumer Research, 19 (1), 62-70.

Mazumdar, Tridib, S. P. Raj, and Indrajit Sinha (2005), "Reference Price Research: Review and Propositions,” Journal of Marketing, 69 (4), 84-102.

and Purushottam Papatla (2000), "An Investigation of Reference Price Segments,” Journal of Marketing Research, 37 (2), 246-258.

and Sung Y. Jun (1992), "Effects of Price Uncertainty on Consumer Purchase Budget and Price Thresholds,” Marketing Letters, 3 (4), 323-29.

Miniard, Paul W., Deepak Sirdeshmukh, and Daniel E. Innis (1992), "Peripheral Persuasion and Brand Choice,” Journal of Consumer Research, 19 (2), 226-39.

Mobley, Mary F., William O. Bearden, and Jesse E. Teel (1988), “An Investigation of Individual Responses to Tensile Price Claims,” Journal of Consumer Research, 15 (2), 273-79.

Monroe, Kent B. (1971), "Measuring Price Thresholds by Psychophysics and Latitudes of Acceptance," Journal of Marketing Research, 8 (4), 460-64. (1973), “Buyers' Subjective Perceptions of Price,” Journal of Marketing Research, 10 (February), 70-80.

Muthén, Linda K. and Bengt O. Muthén (2010), Mplus User’s Guide. Los Angeles, CA: Muthén \& Muthén.

Niedrich, Ronald W., Subhash Sharma, and Douglas H. Wedell (2001), "Reference Price and Price Perceptions: A Comparison of Alternative Models,” Journal of Consumer Research, 28 (3), 339-54. 
Nunes, Joseph C. and Peter Boatwright (2004), "Incidental Prices and their Effect on Willingness to Pay,” Journal of Marketing Research, 41 (4), 457-66.

Palazon, Mariola and Elena Delgado-Ballester (2009), "Effectiveness of price discounts and premium promotions,” Psychology \& Marketing, 26 (12), 1108-29.

Preacher, Kristopher J. and Andrew F. Hayes (2008), "Asymptotic and Resampling Strategies for Assessing and Comparing Indirect Effects in Multiple Mediator Models,” Behavior Research Methods, 40 (3), 879-91.

Raghubir, Priya (1998), “Coupon Value: A Signal for Price?,” Journal of Marketing Research, 35 (3), 316-24.

and Kim Corfman (1999), "When Do Price Promotions Affect Pretrial Brand Evaluations?,” Journal of Marketing Research, 36 (2), 211-22.

Rajendran, K. N. and Gerard J. Tellis (1994), "Contextual and Temporal Components of Reference Price,” Journal of Marketing, 58 (1), 22-34.

Saini, Ritesh, Raghunath S. Rao, and Ashwani Monga (2010), "Is That Deal Worth My Time? The Interactive Effect of Relative and Referent Thinking on Willingness to Seek a Bargain," Journal of Marketing, 74 (1), 34-48.

Skowronski, John J. and Donal E. Carlston (1989), "Negativity and Extremity Biases in Impression Formation: A Review of Explanations," Psychological Bulletin, 105 (1), 131-42.

Suk, Kwanho, Song-Oh Yoon, Donald R. Lichtenstein, and Sie Yeoun Song (2010), "The Effect of Reference Point Diagnosticity on Attractiveness and Intentions Ratings," Journal of Marketing Research, 47 (5), 983-95.

Thaler, Richard (1985), "Mental Accounting and Consumer Choice,” Marketing Science, 4 (3), 199-214.

Tsiros, Michael and David M. Hardesty (2010), "Ending a Price Promotion: Retracting It in One Step or Phasing It Out Gradually,” Journal of Marketing, 74 (1), 49-64.

Urbany, Joel E., William O. Bearden, and Dan C. Weilbaker (1988), "The Effect of Plausible and Exaggerated Reference Prices on Consumer Perceptions and Price Search,” Journal of Consumer Research, 15 (1), 95-110.

Winterich, Karen Page and Michael J. Barone (2011), "Warm Glow or Cold, Hard Cash? Social Identify Effects on Consumer Choice for Donation versus Discount Promotions,” Journal of Marketing Research, 48 (5), 855-68.

Yadav, Manjit S. and Kathleen Seiders (1998), "Is the Price Right? Understanding Contingent Processing in Reference Price Formation,” Journal of Retailing, 74 (Fall), 311-29. 


\section{TABLE 1}

Study 1: Means, Standard Deviations and Correlation Matrix

\begin{tabular}{|c|c|c|c|c|c|c|c|c|c|}
\hline Variables & 1 & 2 & 3 & 4 & 5 & 6 & 7 & 8 & 9 \\
\hline $\begin{array}{l}\text { 1. Price Promotion Treatment } \\
\text { (RPD (0) vs. GPD (1)) }\end{array}$ & - & & & & & & & & \\
\hline $\begin{array}{l}\text { 2. Price Promotion Treatment } \\
\text { (RPD (0) vs. Control (1)) }\end{array}$ & -.57 & - & & & & & & & \\
\hline 3. $\mathrm{IRP}_{\mathrm{t} 1}$ & .06 & -.05 & - & & & & & & \\
\hline 4. $\mathrm{IRP}_{\mathrm{t} 2}$ & .18 & .09 & .68 & - & & & & & \\
\hline 5. $I R P_{t 3}$ & .12 & .04 & .58 & .67 & - & & & & \\
\hline 6. Quality Perception ${ }_{\mathrm{t} 1}$ & .01 & .03 & .20 & .14 & .10 & - & & & \\
\hline 7. Quality Perception ${ }_{\mathrm{t} 2}$ & .11 & .10 & .15 & .22 & .07 & .41 & - & & \\
\hline 8. Quality Perception ${ }_{\mathrm{t} 3}$ & .07 & .06 & .11 & .14 & .15 & .30 & .41 & - & \\
\hline 9. Shopping Frequency & .01 & .09 & -.03 & -.01 & .05 & .18 & .11 & .18 & - \\
\hline Means & .31 & .42 & 2.22 & 2.14 & 2.15 & 4.62 & 4.59 & 4.58 & 4.13 \\
\hline SD & .46 & .49 & .47 & .46 & .50 & .96 & 1.03 & 1.16 & 1.54 \\
\hline
\end{tabular}


TABLE 2

Validity Checks of Studies 1 and 2

\begin{tabular}{|c|c|c|c|c|}
\hline \multicolumn{5}{|c|}{ Study 1} \\
\hline Variable & GPD & RPD & Control & Test of significance \\
\hline Awareness of the Deal & 5.20 & 5.13 & - & $\Delta \mathrm{M}=.07, \mathrm{t}=.23, \mathrm{~ns}$ \\
\hline $\begin{array}{l}\text { Attractiveness of the } \\
\text { Deal }\end{array}$ & 5.74 & 5.82 & - & $\Delta \mathrm{M}=.08, \mathrm{t}=.77, \mathrm{~ns}$ \\
\hline Share of GPD Winners & $53 \%$ & - & - & - \\
\hline $\begin{array}{l}\text { GPD Win vs. Loss } \\
\text { Check: } \\
\text { Internal Reference } \\
\text { Price }\end{array}$ & $\begin{array}{l}\text { Winners: } 2.17 € \\
\text { Losers: } 2.23 €\end{array}$ & $1.97 €$ & $2.18 €$ & $\begin{array}{l}\Delta \mathrm{M}_{\mathrm{GPD} \text { Win/Loss }}=.06, \mathrm{t}= \\
.573, \mathrm{~ns}\end{array}$ \\
\hline Age & 25.4 & 24.3 & 25.7 & $\mathrm{~F}(\mathrm{df}=2)=1.3, \mathrm{~ns}$ \\
\hline Gender [\%male] & 38.6 & 41.1 & 44.7 & $\mathrm{X}^{2}(\mathrm{df}=2)=.96, \mathrm{~ns}$ \\
\hline \multicolumn{5}{|c|}{ Study 2} \\
\hline Awareness of the Deal & 5.08 & 5.15 & - & $\Delta \mathrm{M}=.07, \mathrm{t}=.18, \mathrm{~ns}$ \\
\hline $\begin{array}{l}\text { Attractiveness of the } \\
\text { Deal }\end{array}$ & 5.80 & 5.77 & - & $\Delta \mathrm{M}=.03, \mathrm{t}=.15, \mathrm{~ns}$ \\
\hline Share of GPD Winners & $51 \%$ & - & - & - \\
\hline $\begin{array}{l}\text { GPD Win vs. Loss } \\
\text { Check: } \\
\text { Internal Reference } \\
\text { Price } \\
\text { GPD Win vs. Loss }\end{array}$ & $\begin{array}{l}\text { Winners: } 2.15 € \\
\text { Losers: } 2.12 €\end{array}$ & $1.97 €$ & $2.13 €$ & $\begin{array}{l}\Delta \mathrm{M}_{\mathrm{GPD} \text { Win/Loss }}=.03, \mathrm{t}= \\
.28, \mathrm{~ns}\end{array}$ \\
\hline $\begin{array}{l}\text { Check: } \\
\text { Share of } \\
\text { Repurchasing } \\
\text { Customers }\end{array}$ & $\begin{array}{l}\text { Winners: .71 } \\
\text { Losers: .68 }\end{array}$ & .54 & .73 & $\begin{array}{c}\mathrm{X}^{2}(\mathrm{df}=1)_{\mathrm{GPD} \text { Win/Loss }}= \\
1.62, \mathrm{~ns}\end{array}$ \\
\hline Age & 29.09 & 28.34 & 27.84 & $\mathrm{~F}(\mathrm{df}=2)=.66, \mathrm{~ns}$ \\
\hline Gender [\%male] & $50.8 \%$ & $58.5 \%$ & $52.5 \%$ & $\mathrm{X}^{2}(\mathrm{df}=2)=1.12, \mathrm{~ns}$ \\
\hline
\end{tabular}


TABLE 3

Study 1: Results of the Longitudinal Structural Equation Model

\begin{tabular}{|c|c|c|c|c|c|}
\hline & & & Full Model & $\begin{array}{c}\text { Model GPD } \\
\text { Winners }\end{array}$ & $\begin{array}{l}\text { Model GPD } \\
\text { Losers }\end{array}$ \\
\hline \multicolumn{6}{|c|}{ Hypothesized Treatment Effects } \\
\hline RPD (0) vs. GPD (1) & $\rightarrow$ & $\mathrm{IRP}_{\mathrm{t} 2}(\mathrm{H} 1:+)$ & $.20^{\star \star \star}$ & $.17^{\star \star \star}$ & $.17^{\star \star \star}$ \\
\hline RPD (0) vs. Control (1) & $\rightarrow$ & $\mathrm{IRP}_{\mathrm{t} 2}(\mathrm{H} 1:+)$ & $.17^{\star \star \star}$ & $.18^{\star \star \star}$ & $.17^{\star \star \star}$ \\
\hline \multicolumn{6}{|c|}{ Control Effects } \\
\hline \multicolumn{6}{|c|}{ Control: Direct Treatment Effects } \\
\hline RPD (0) vs. GPD (1) & $\rightarrow$ & $\mathrm{IRP}_{\mathrm{t} 1}$ & $.05^{\mathrm{ns}}$ & $.05^{\mathrm{ns}}$ & $.09^{\text {ns }}$ \\
\hline RPD (0) vs. Control (1) & $\rightarrow$ & $\mathrm{IRP}_{\mathrm{t} 1}$ & $-.03^{\text {ns }}$ & $-.04^{\text {ns }}$ & $-.04^{\text {ns }}$ \\
\hline RPD (0) vs. GPD (1) & $\rightarrow$ & $\mathrm{IRP}_{\mathrm{t} 3}$ & $.01^{\text {ns }}$ & $.01^{\mathrm{ns}}$ & $.02^{\mathrm{ns}}$ \\
\hline RPD (0) vs. Control (1) & $\rightarrow$ & $\mathrm{IRP}_{\mathrm{t} 3}$ & $-.01^{\text {ns }}$ & $-.01^{\mathrm{ns}}$ & $-.01^{\mathrm{ns}}$ \\
\hline \multicolumn{6}{|c|}{ Control: Autoregressive Effects } \\
\hline $\mathrm{IRP}_{\mathrm{t} 1}$ & $\rightarrow$ & $\mathrm{IRP}_{\mathrm{t} 2}$ & $.66^{\star \star \star}$ & $.59^{\star \star \star}$ & $.68^{\star \star \star}$ \\
\hline $\mathrm{IRP}_{\mathrm{t} 2}$ & $\rightarrow$ & $\mathrm{IRP}_{\mathrm{t} 3}$ & $.67^{\star \star \star}$ & $.64^{\star \star \star}$ & $.70^{\star \star \star}$ \\
\hline \multicolumn{6}{|c|}{ Control: Shopping Frequency Effect } \\
\hline Shopping Frequency & $\rightarrow$ & $\mathrm{IRP}_{\mathrm{t} 1}$ & $-.07^{\mathrm{ns}}$ & $-.08^{\mathrm{ns}}$ & $-.10^{*}$ \\
\hline Shopping Frequency & $\rightarrow$ & $\mathrm{IRP}_{\mathrm{t} 2}$ & $-.01^{\mathrm{ns}}$ & $.01^{\mathrm{ns}}$ & $.03^{\mathrm{ns}}$ \\
\hline Shopping Frequency & $\rightarrow$ & $\mathrm{IRP}_{\mathrm{t} 3}$ & $.04^{\mathrm{ns}}$ & $.05^{\mathrm{ns}}$ & $.05^{\mathrm{ns}}$ \\
\hline \multicolumn{6}{|c|}{ Control: Quality Perception } \\
\hline Quality Perception ${ }_{\mathrm{t} 1}$ & $\rightarrow$ & $\mathrm{IRP}_{\mathrm{t} 1}$ & $.22^{\star \star \star}$ & $.19^{\star \star \star}$ & $.24^{\star \star \star}$ \\
\hline Quality Perception $\mathrm{t} 2$ & $\rightarrow$ & $\mathrm{IRP}_{\mathrm{t} 2}$ & $.12^{\star \star}$ & $.17^{\star \star \star}$ & $.11^{\star \star}$ \\
\hline Quality Perception ${ }_{\mathrm{t} 3}$ & $\rightarrow$ & $\mathrm{IRP}_{\mathrm{t} 3}$ & $.11^{\star \star}$ & $.12^{\star \star}$ & $.10^{\star \star}$ \\
\hline CFI (TLI) & & & $.96(.92)$ & $.95(.91)$ & $.96(.94)$ \\
\hline
\end{tabular}

Notes. Standardized coefficients are shown. ${ }^{* * *} p<.01,{ }^{* *} p<.05,{ }^{*} p<.1$, ns $=$ not significant (two-tailed). 
TABLE 4

Studies 1 and 2: IRP Cell Means per Experimental Condition

\begin{tabular}{lcccccc}
\hline & \multicolumn{3}{c}{ Study 1 } & \multicolumn{3}{c}{ Study 2 } \\
\hline & IRP $_{\mathbf{t} 1}$ & IRP $_{\mathbf{t} 2}$ & $\mathbf{I R P}_{\mathbf{t} 3}$ & $\mathbf{I R P}_{\mathbf{t} 1}$ & $\mathbf{I R P}_{\mathbf{t} 2}$ & $\mathbf{I R P}_{\mathbf{t} 3}$ \\
\hline RPD & $2.19^{\mathrm{a}}$ & $1.97^{\mathrm{b}}$ & $2.00^{\mathrm{b}}$ & $2.13^{\mathrm{a}}$ & $1.98^{\mathrm{b}}$ & $2.01^{\mathrm{b}}$ \\
GPD & $2.24^{\mathrm{a}}$ & $2.20^{\mathrm{c}}$ & $2.21^{\mathrm{c}}$ & $2.11^{\mathrm{a}}$ & $2.13^{\mathrm{c}}$ & $2.10^{\mathrm{c}}$ \\
Control & $2.20^{\mathrm{a}}$ & $2.18^{\mathrm{c}}$ & $2.19^{\mathrm{c}}$ & $2.10^{\mathrm{a}}$ & $2.13^{\mathrm{c}}$ & $2.11^{\mathrm{c}}$ \\
\hline
\end{tabular}

Notes. RPD = regular price discount, GPD = gambled price discount, IRP = internal reference price (measured in $€$ )

${ }^{\mathrm{a}}$ No significant $\mathrm{IRP}_{\mathrm{t} 1}$ differences between conditions.

${ }^{\mathrm{b}} \mathrm{RPD} \mathrm{IRP}_{\mathrm{t} 2 / \mathrm{t}}$ is significantly lower than GPD and control at $p<.05$

cno significant difference between GPD and control (all two-tailed). 
TABLE 5

Study 2: Descriptive Statistics of Key Variables

\begin{tabular}{|c|c|c|c|c|}
\hline Condition & $\begin{array}{c}\text { Repurchase }_{\mathbf{t 3}} \\
\text { \% of customers per condition who } \\
\text { repurchased } \\
\end{array}$ & $\begin{array}{c}\text { Sale Price } \\
\text { Atypicality } 2\end{array}$ & $\begin{array}{l}\text { Sale Price } \\
\text { Uncertainty } 12\end{array}$ & $\begin{array}{c}\text { Internal } \\
\text { Reference } \\
\text { Price }_{\mathrm{t} 2} \\
\end{array}$ \\
\hline GPD & $70,1 \%$ & 4.99 & 4.51 & $2.13 €$ \\
\hline RPD & $53,8 \%$ & 4.53 & 3.76 & $1.98 €$ \\
\hline No-Discount Control & $72,5 \%$ & $-{ }^{a}$ & $-{ }^{a}$ & $2.13 €$ \\
\hline \multicolumn{5}{|c|}{ Comparison of Repurchase Distributions } \\
\hline GPD vs. RPD & $X^{2}(1,131)=3.727, p<.05$ & & & \\
\hline RPD vs. Control & $x^{2}(1,104)=3.620, p<.05$ & - & - & - \\
\hline GPD vs. Control & $x^{2}(1,106)=.062, n s$ & & & \\
\hline
\end{tabular}


FIGURE 1

Overview of the Conceptual Framework

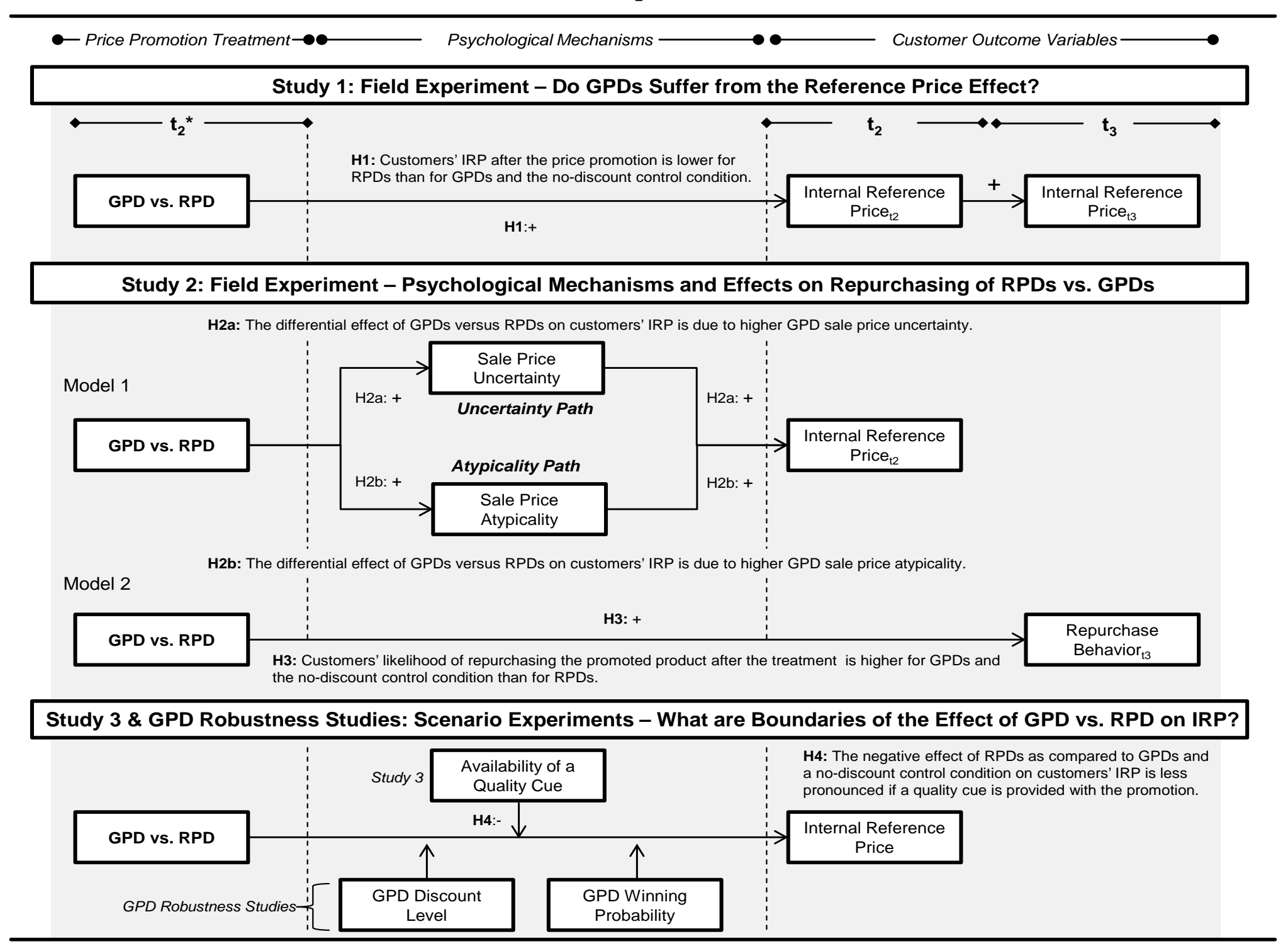

Notes. GPD = gambled price discount; RPD = regular price discount; ${ }^{{ }_{1}}{ }_{1}$ serves as a premeasurement; GPD is always coded as 1 and RPD as 0. 
FIGURE 2

Study 3: Interaction Diagram of Availability of a Quality Cue and Price Promotion Treatment

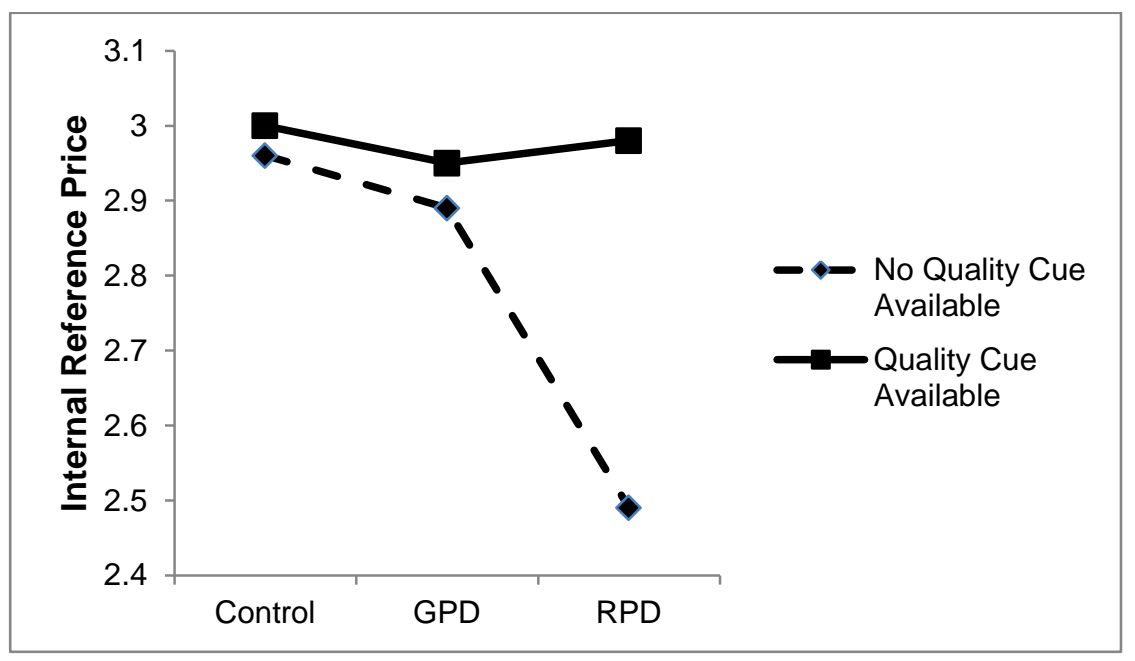




\section{APPENDIX}

\begin{tabular}{|c|c|c|c|}
\hline Construct & Items & CA & Source \\
\hline $\begin{array}{l}\text { Internal } \\
\text { reference price } \\
\text { [in €] }\end{array}$ & $\begin{array}{l}\text { - Please estimate the average market price for the fast } \\
\text { food }^{\mathrm{a}}:{ }{ }^{-} \text {Please indicate what you consider a fair price for the } \\
\text { fast-food meal: }\end{array}$ & $.74-.81$ & $\begin{array}{l}\text { Adopted from Grewal, } \\
\text { Monroe, and Krishnan } \\
\text { (1998); Lichtenstein, } \\
\text { Burton, and Karson } \\
\text { (1991) }\end{array}$ \\
\hline $\begin{array}{l}\text { Quality } \\
\text { perception }^{\mathrm{a}}\end{array}$ & $\begin{array}{l}\text { - The fast-food meal appears to be of good quality. } \\
\text { - The fast-food meal seems to be a premium product. } \\
\text { - The fast-food meal seems to contain high quality } \\
\text { ingredients. }\end{array}$ & .90 & $\begin{array}{l}\text { Adopted from Grewal, } \\
\text { Monroe, and Krishnan } \\
\text { (1998) }\end{array}$ \\
\hline $\begin{array}{l}\text { Repurchase } \\
\text { behavior }\end{array}$ & $\begin{array}{l}\text { Customers' actual repurchasing behavior tracked by } \\
\text { observer; coded } 1 \text { if the customer purchased the focal } \\
\text { fast-food meal and } 0 \text { if the customer did not purchase the } \\
\text { focal fast -food meal. }\end{array}$ & - & $\begin{array}{l}\text { Own } \\
\text { operationalization }\end{array}$ \\
\hline $\begin{array}{l}\text { Shopping } \\
\text { frequency }^{\mathrm{a}}\end{array}$ & $\begin{array}{l}\text { I purchase the fast-food meal frequently (7)/infrequently } \\
\text { (1). }\end{array}$ & - & $\begin{array}{l}\text { Own } \\
\text { operationalization }\end{array}$ \\
\hline $\begin{array}{l}\text { Sale price } \\
\text { uncertainty }\end{array}$ & $\begin{array}{l}\text { - I am very uncertain about the sale price that I will } \\
\text { finally receive. } \\
\text { - I am very uncertain what price I have to pay at this } \\
\text { price promotion. }\end{array}$ & $.78-.82$ & $\begin{array}{l}\text { Own } \\
\text { operationalization, } \\
\text { based on Laran and } \\
\text { Tsiros (2013) }\end{array}$ \\
\hline $\begin{array}{l}\text { Sale price } \\
\text { atypicality }^{\mathrm{a}}\end{array}$ & $\begin{array}{l}\text { - The sale price appears to me as exceptionally low. } \\
\text { - To me, the sale price seems to be unusually low. }\end{array}$ & $.87-.94$ & $\begin{array}{l}\text { Based on Monroe } \\
\text { (1971), Kopalle and } \\
\text { Lindsey-Mullikin } \\
\text { (2003), and } \\
\text { Chandrashekaran and } \\
\text { Grewal (2003) }\end{array}$ \\
\hline $\begin{array}{l}\text { Induced } \\
\text { purchase } \\
\text { incentive by the }_{\text {promotion }^{\mathrm{a}}}\end{array}$ & $\begin{array}{l}\text { The price promotion induced me to buy the fast-food } \\
\text { meal. }\end{array}$ & - & $\begin{array}{l}\text { Own } \\
\text { operationalization }\end{array}$ \\
\hline $\begin{array}{l}\text { Awareness of } \\
\text { the deal }^{\mathrm{a}}\end{array}$ & $\begin{array}{l}\text { I was fully aware of the price promotion for the fast-food } \\
\text { meal today. }\end{array}$ & - & $\begin{array}{l}\text { Own } \\
\text { operationalization }\end{array}$ \\
\hline $\begin{array}{l}\text { Age } \\
\text { Gender }\end{array}$ & $\begin{array}{l}\text { Please indicate your age: } \_ \text {years } \\
\text { Please indicate your gender: male / female } \\
\text { Please select your income level from the following }\end{array}$ & - & - \\
\hline Income & $\begin{array}{l}\text { categories: <500€; 500-1000€; 1001-1500€; 1501-2000€, } \\
>2000 €\end{array}$ & - & - \\
\hline
\end{tabular}

Notes. CA = Cronbach’s alpha; a = 7-point Likert-Scale; $(r)$ = reverse coded.

aThe product in the item formulation is adjusted according to the respective study's stimulus. 